Paranoia como catástrofe social

\title{
Paranoia Como catástrofe social: SObre O PROBLEMA DA GÊNESE DE CATEGORIAS CLÍNICAS
}

Vladimir Safatle

RESUMO: trata-se de discutir as relações entre a constituição da paranoia como categoria clínica e experiências estético-sociais de crise. Esta é uma maneira de se perguntar sobre as relações que categorias clínicas tecem com processos e valores advindos dos campos da política e da estética.

PALAVRAS-CHAVE: Paranoia. Freud. Lacan. Sofrimento social. Literatura. Linguagem.

\author{
- Aqui estão os textos que ela escreve, \\ e o que ela escreve é o mesmo que escrevo. \\ James Joyce a Jung, \\ sobre sua filha psicótica Lúcia Joyce. \\ - Mas onde você nada, ela se afoga. \\ Jung a James Joyce.
}

O que é uma categoria constituída para dirigir os modos de intervenção clínica diante de doenças mentais? Qual a sua gênese e o que está em jogo, em sua "descoberta"? O que queremos realmente dizer, quando afirmamos termos individualizado e definido uma categoria capaz de guiar nossos modos de intervenção clínica, como transtorno obsessivo-compulsivo, paranoia, transtorno esquizofreniforme?

Estas não são questões simples e tocam, de maneira central, nossa compreensão sobre a estrutura de racionalidade própria às práticas clínicas. No entanto, em uma primeira abordagem, temos a impressão de que, ao contrário, trata-se de questões relativamente triviais. Uma categoria clínica é definida

\footnotetext{
${ }^{1}$ Professor Livre-Docente do Departamento de Filosofia da Universidade de São Paulo, professor visitante das universidades de Paris VII, Paris VIII, Toulouse e Louvain, bolsista de produtividade do $\mathrm{CNPq}$.

Trans/Form/Ação, Marilia, v. 34, n. 2, p. 215-236, 2011
} 
enquanto tal, quando ela demonstra sua eficácia, ou seja, quando ela é capaz de ser uma peça importante no desenvolvimento de um processo de tratamento, de uma dinâmica terapêutica que deve nos levar àquilo que chamamos de "cura". E, a respeito da noção de "cura", não haveria razão para problematizá-la de maneira excessiva. Há um fato bruto, fato que fala por si mesmo, a saber, a clínica tem diante de si um sujeito que sofre. Para além de toda e qualquer questão de método e de definição de objeto, a clínica está sempre diante do sofrimento do paciente, uma realidade inabalável. Minorar o sofrimento é nossa função e o único critério de orientação da clínica. Dessa forma, a cura não seria outra coisa que a redução do sofrimento ao silêncio, já que, como dizia o médico René Leriche, “[...] a saúde é a vida no silêncio dos órgãos”. Um pouco como se a eficácia terapêutica em relação a uma categoria fenomênica extremamente normativa como o "sofrimento" fosse condição suficiente para a validade de dispositivos clínicos.

Mas podemos fazer, aqui, uma pergunta maior: e se a noção de cura não for autoevidente, como parece ser a princípio? Lembremos apenas o que a perspectiva acima descrita tem de ideológica. Pois é ideológico todo sistema de saber e de orientação da praxis que procura naturalizar seus dispositivos de justificação como se estivéssemos diante de "fatos que falam por si mesmos". Nesse sentido, podemos perguntar: afinal, o sofrimento é um "fato que fala por si mesmo" ou é um fenômeno que é levado a falar no interior de contextos sóciohistóricos determinados? Podemos, por exemplo, extrair as consequências de afirmações como esta, de Foucault:

\begin{abstract}
Desde o século XVIII, a medicina tem tendência a narrar sua própria história como se o leito dos doentes tivesse sido sempre um lugar de experiências constante e estável, em oposição às teorias e sistemas que teriam estado em permanente mudança e mascarado, sob sua especulação, a pureza da evidência clínica". Na verdade, tudo se passaria como se: "Na aurora da Humanidade, antes de toda crença vã, antes de todo sistema, a medicina residia em uma relação imediata do sofrimento com aquilo que alivia"’2.
\end{abstract}

Tal pressuposição de imediaticidade, no entanto, esquece como "o que nos faz sofrer" muda constantemente de configuração. Não se sofre da mesma forma, em todas as épocas e lugares. Mesmo a sensibilidade ao sofrimento muda de acordo com determinações sociais, já que o sofrimento é normalmente compreendido como restrição da capacidade de ação e decisão, e sabemos o quanto "ação" e "decisão" são processos que só têm sentido no interior de contextos sociais. É possível que a significação do sofrimento seja uma questão eminentemente política, já que diz respeito à maneira com que os corpos sofrerão interferências,

${ }^{2}$ FOUCAULT, Michel. Naissance de la clinique. Paris: PUF, 2005, p. 53. 
os comportamentos serão normatizados, os processos de socialização e de reprodução de modos de vida serão defendidos. Ou seja, diz respeito à maneira como a "saúde" aparece enquanto categoria fundamental de imposição de uma normatividade social à vida.

Entretanto, poderíamos tentar dizer que a experiência da dor é algo que ancora o sofrimento em um solo inquestionável e indiferente a contextos. Mas, novamente, não seria difícil verificar como não há nenhuma relação imediata entre a dor física e o desprazer de um sofrimento vivenciado como doença que leva sujeitos a se submeterem à clínica. Basta lembrar, aqui, das palavras de um "psicólogo", Nietzsche:

\begin{abstract}
Somente a grande dor, aquela longa, lenta dor, que leva tempo, em que somos queimados, queimamos como madeira verde, obriga a nós, filósofos, a descer a nossa última profundeza e a tirarmos de nós toda confiança [...] Duvido que tal dor nos deixe melhor, mas eu sei que ela nos aprofunda3.
\end{abstract}

Ou seja, há algumas dores e desconfortos que procuramos, não devido a algum fantasma masoquista, mas por compreendermos que o que está em jogo nessas situações é alguma forma necessária de ruptura importante no interior de um processo de formação e maturação.

Sendo assim, temos sempre o direito de perguntar de onde vem isto que poderíamos chamar de "gramática da doença", ou seja, esse modo com que o saber transforma a doença em discurso pronto para ser lido e interpretado. Todavia, a pergunta sobre a gramática da doença equivale também a uma pergunta sobre a verdadeira direção dos dispositivos clínicos. Pois o caráter bem-sucedido da intervenção clínica é indissociável da constituição do horizonte regulador da cura, da definição do que estamos dispostos a contar como "saúde" e "doença".

Posta essa articulação, há, grosso modo, dois procedimentos. O primeiro consiste em compreender o julgamento a respeito dos estados de doença e saúde como um julgamento descritivo vinculado à descrição de variáveis orgânicas individualizadas, de déficits e excessos quantitativamente mensuráveis. Nessa perspectiva, a diferença entre normal e patológico aparece como uma diferença quantitativa que diria respeito a funções e órgãos isolados, como se os fenômenos patológicos fossem, no organismo vivo, apenas variações quantitativas, déficits ou excessos. Quer dizer, a doença nada mais seria do que um subvalor derivado do normal. É a definição do normal como estrutura positiva que define o campo da clínica. Tal experiência clínica exige que o normal esteja assentado em um campo mensurável acessível à observação. Tal campo privilegiado é a fisiologia que

${ }^{3}$ NIETZSCHE, Friedrich. A gaia ciência. In: Obras incompletas. São Paulo: Nova Cultural, 1987, p. 147. 
aparece, assim, como fundamento para uma clínica que irá se orientar a partir dos postulados de uma anatomia patológica: "As técnicas de intervenção terapêutica só podem ser secundárias em relação à ciência fisiológica, isto na medida em que o patológico só tem realidade provisória por declinação do normal"4. O que nos deixa com uma questão maior: o que deve acontecer ao corpo, para que a fisiologia possa aparecer como campo de determinação da normatividade da vida, campo de identificação daquilo que deve valer para a clínica como norma? Questão que será retomada por Foucault, em O nascimento da clínica, ao lembrar que

[...] o que é modificado com o advento da medicina anatomo-clínica não é a simples superfície de contato entre o sujeito cognoscente e o objeto conhecido; é a disposição mais geral do saber que determina as posições recíprocas e o jogo mútuo deste que deve conhecer e o que há a conhecer ${ }^{5}$.

Mas a consequência maior de tal perspectiva é a compreensão de que as intervenções clínicas seriam simplesmente processos que visam reconstruir o valor de certas variáveis quantitativamente mensuráveis, cuja natureza final é orgânica, neuronal ou fisiológica. Vemos isto, por exemplo, através da constituição da depressão como categoria clínica capaz de justificar um modo específico de intervenção medicamentosa. A "descoberta" de que a depressão seria um desequilíbrio dos mecanismos de produção e recaptação de neurotransmissores como a serotonina e a dopamina, isto a partir dos anos 1960, permitiu o estabelecimento de uma equação causal entre estado cerebral e estado mental. Tal equação propiciou que o olhar médico pudesse determinar a existência da doença. Na verdade,

[...] quando surgiu o primeiro antidepressivo, em 1956, o laboratório Geigy, que
o sintetizou, chegou a hesitar em comercializá-lo, pois considerava o mercado de
depressão insignificante. Na verdade, a imipramina foi inicialmente sintetizada
pela Geigy para ser um antipsicótico, tendo uma estrutura química bastante
semelhante a da clorpromazina, do laboratório concorrente Rhône-Poulenc ${ }^{6}$.

De uma certa forma, a possibilidade de estabelecer uma equação entre estado cerebral e um conjunto vago de estados mentais, que deveriam ser vistos como desagradáveis, permitiu a construção de uma categoria clínica como a "depressão", que, até então, não era exatamente uma categoria clínica. Isto patrocinou a transformação do tratamento em uma espécie de acompanhamento e gestão dos efeitos da medicalização (o que possibilitou que a venda de

\footnotetext{
${ }^{4}$ CANGUILHEM, Georges. O normal e o patológico. Rio de Janeiro: Forense, 2002, p. 42.

5 FOUCAULT, Michel. Naissance de la clinique, p. 139.

${ }^{6}$ AGUIAR, Adriano. A psiquiatria no divã. Rio de Janeiro: Relume Dumará, p. 94. 
antidepressivos sob prescrição médica, no Brasil, chegasse, em 2008, à soma de 842,4 milhões de reais).

Contudo, há uma outra forma de compreender a doença e, por consequência, a cura e a natureza das intervenções clínicas. Ao invés de utilizar um julgamento descritivo a respeito da doença, podemos compreendê-la através de um julgamento valorativo, vinculado à consciência do decréscimo de capacidades e habilidades. Vincular a doença não mais a variáveis orgânicas individualizadas, mas a valores qualitativamente determinados e compreendidos como tais pelo doente.

A esse respeito, lembremos como há uma outra perspectiva de análise das distinções entre normal e patológico, que insiste na distinção qualitativa, e não meramente quantitativa, entre os dois. Tal perspectiva teria, ao menos, duas versões. Uma deveria ser chamada de teoria ontológica, devido ao fato de encarar a doença como o resultado da presença do que tem realidade ontológica distinta do corpo são. A teoria microbiana das doenças contagiosas (Pasteur) seria um caso paradigmático, aqui, por fornecer, através do micróbio, uma "representação ontológica do mal", positivamente localizada.

Já a outra deveria ser chamada de teoria dinamista ou funcional, e encontra na medicina grega seu exemplo fundador. Contrariamente a uma noção de doença determinada a partir da possibilidade de localização, a medicina grega estaria marcada por um certo dinamismo relacional, que insiste no aspecto determinante das relações entre organismo e meio-ambiente: "A natureza (physis) tanto no homem como fora dele, é harmonia e equilíbrio. A perturbação desse equilíbrio, dessa harmonia, é a doença. Nesse caso, a doença não está em alguma parte no homem. Está em todo o homem e é toda dele"7 . A doença aparece, assim, como um acontecimento que diz respeito ao organismo vivo, encarado na sua totalidade, pois “[...] não há um único fenômeno que se realize no organismo doente da mesma forma como no organismo são" ". Quando classificamos como patológico um sistema ou um mecanismo funcional isolado, esquecemos que aquilo que os tornam patológicos é a relação de inserção na totalidade indivisível de um comportamento individual. Canguilhem chega mesmo a afirmar que ser doente é, para o homem, viver uma vida diferente. Observemos, ainda, que tal estratégia de associar o normal a uma relação normativa de ajustamento ao meio implica afirmar que não há fato algum que seja normal ou patológico em si. Eles são normais e patológicos no interior de uma relação entre organismo e meio ambiente.

\footnotetext{
7 CANGUILHEM, ibidem, p. 20.

${ }^{8}$ Idem, p. 52. 
No entanto, é nesse ponto que algumas questões devem ser complexificadas. Devemos, pois, levar ao extremo a compreensão de que o meio-ambiente vital do ser humano não é um meio natural bruto, mas um meio social, construído através de valores reguladores que internalizamos e que guiam a maneira com que estruturamos o sentido e a orientação das relações a si, assim como das relações ao corpo. Tais valores são fundamentais na determinação geral dos padrões de saúde e dos vetores de orientação dos processos de cura. Mas, se assim for, temos todo o direito de nos perguntar: qual a genealogia de tais valores presentes no horizonte de toda demanda de cura, qual o processo complexo que os gera? Como tais valores interferem na determinação do que é uma doença mental, qual sua estrutura e característica? Seriam tais valores derivados de valores estéticos (basta pensarmos na natureza sobredeterminada de termos como "harmonia" e "equilíbrio"), políticos (pensemos o mesmo para "capacidade de controle e decisão”), entre outros?

\section{A SOMBRA DA RAZÃo: VALORES POLÍTICOS}

Esta é a questão que gostaria de colocar. $\mathrm{Na}$ verdade, trata-se de procurar uma maneira possível de se perguntar sobre que tipo de fenômeno é uma doença mental, o que ela descreve exatamente (um conjunto de sintomas de comportamento, déficits orgânicos, modos de relação social, tipos de conduta desviantes em relação a um padrão normal, descrições de sofrimentos e de restrições da capacidade de ação). Para tanto, poderíamos partir de uma categoria presente até hoje na clínica psicanalítica e, de certa forma, na clínica psiquiátrica, a saber, a paranoia. Essa escolha da paranoia ou, se quisermos utilizar a definição que encontramos atualmente no DSM IV, a esquizofrenia do tipo paranoide, justifica-se pela perenidade de seu uso e pela estabilidade de sua definição.

$\mathrm{Na}$ estrutura clínica psicanalítica, ela é ainda concebida como um dos três quadros nosográficos próprios à estrutura psicótica, juntamente com a esquizofrenia e a melancolia (ou psicose maníaco-depressiva). Sua caracterização atual não é muito distinta daquela que encontramos em Freud. Desde 1895, Freud compreendia a paranoia como um "[...] modo patológico de defesa", que se servia de mecanismos como o delírio ${ }^{10}$ e uma forte tendência à projeção de representações inconciliáveis com a coerência ideal do Eu. À ocasião de seu texto paradigmático relativo ao caso Schreber, tais mecanismos de defesa

\footnotetext{
${ }^{9}$ Ver FREUD; Sigmund. Manuscrit H. In: La naissance de la psychanalyse. Paris: PUF, 1996, p. 98.

${ }^{10}$ Sendo que, em Freud, o delírio paranoico é “[...] uma tradução em representações de palavras do reprimido que retornou maciçamente na forma de signos perceptuais" (SIMANKE, Richard. $A$ formação da teoria freudiana das psicoses. Belo Horizonte: Loyola, 2008, p. 100). 
encontrarão seu fundamento em uma desesperada reação contra um certo impulso homossexual impossível, por razões estruturais, de ser vivenciado como tal pelo sujeito. Isso demonstrava como Freud estava muito mais interessado em uma determinação causal específica do que em uma pretensa descrição diferencial dos sintomas paranoicos.

Por trás dessa temática aparentemente muito redutora, ligada à defesa contra a homossexualidade (que, no limite, nos obrigaria à tese incorreta do ponto de vista da fenomenologia clínica, referente à impossibilidade de alguém ser, ao mesmo tempo, paranoico e homossexual explícito), há, no entanto, o que poderíamos chamar de uma intuição psicanalítica fundamental a respeito das psicoses. Ela se refere à impossibilidade de alguma forma de mediação simbólica das identificações e da alteridade, devido à fixação em um estado de desenvolvimento e de maturação, que Freud chamava de "narcísico". Assim, devido a tal fixação, todo reconhecimento de si em um outro aparece como anulação catastrófica dos regimes de identidade que, até então, sustentavam uma certa estabilidade prépsicótica. O problema da defesa contra o homossexualismo é, no fundo, modo freudiano de dizer que, na psicose paranoica, todo reconhecimento de si em um outro é vivenciado de maneira ameaçadora e muito invasiva ${ }^{11}$, o que coloca uma personalidade formada a partir da internalização de identificações em rota contínua de colapso. Notemos ainda como tal situação indica um certo modo de ligação defensiva à identidade, de negação da "interioridade da diferença", que demonstram a fragilidade, no caso da psicose, dos modos de síntese psíquica fundadas na noção funcional de Eu. Essa ideia da psicose como fragilidade estrutural do processo de produção de identidades subjetivas aparecerá de maneira mais sistemática nos trabalhos de Jacques Lacan.

Já no interior das práticas psiquiátricas, a paranoia é atualmente definida pelo DSM IV como um subtipo da esquizofrenia - fala-se, atualmente, em esquizofrenia de tipo paranoide, juntamente com outros quatro tipos: desorganizado (caracterizado pelo discurso e pensamento desorganizado, além de afeto inadequado), catatônico (caracterizado por uma acentuada perturbação motora, como imobilidade, atividade excessiva, extremo negativismo, mutismo etc.), indiferenciado (esquizofrenia que não se enquadra nos outros três tipos)

11 A esse respeito, podemos lembrar como, no caso Schreber, a produção delirante transformou-se em modo de estabilização para tal conflito psíquico. Haja vista um delírio como: "Quando falo de cultivo da volúpia, que se tornou como que um dever para mim, não quero dizer jamais um desejo sexual por outras pessoas (mulheres) ou um contato sexual com elas, mas sim que represento a mim mesmo como homem e mulher numa só pessoa, consumando o coito comigo mesmo, realizando comigo mesmo certas ações que visam a excitação sexual, ações que de outra forma seriam consideradas indecorosas, e das quais se deve excluir qualquer idéia de onanismo ou coisas do gênero" (SCHREBER, Daniel Paul; Memória de um doente dos nervos, São Paulo: Paz e Terra, 1986, p. 218). 
e residual (quando há apenas um episódio de esquizofrenia, mas o quadro clínico não apresenta sintomas psicóticos positivos proeminentes). Enquanto subtipo, a paranoia seria marcada, principalmente, pela consistência sistemática das interpretações delirantes (perseguição, erotomania, ciúme, grandeza etc.) e pela ausência de deterioração intelectual. Por sua vez, sua causalidade seria sindrômica, já que seria o resultado de uma articulação entre fatores psicológicos e vulnerabilidades constitucionais (genéticos e obstétricos) ${ }^{12}$.

Sabemos que a paranoia é certamente uma das categorias clínicas mais antigas de que temos notícia. Sua raiz grega não nos deixa dúvidas. Paranoia vem do grego para e nous, ou seja, algo como "ao lado do espírito", fora do que deve ser o espírito. No entanto, é só em meados do século XIX que ela ganha sistematização, principalmente através do Tratado de psiquiatria (1879), do psiquiatra alemão Richard Krafft Ebing, além dos esforços posteriores de classificação desenvolvidos por Emil Kraepelin. Desde o início de sua sistematização, a paranoia conservou-se como modalidade de doença mental cuja característica essencial era aquilo que podemos ainda encontrar no DSM IV, a saber: "[...] presença de delírios ou alucinações auditivas proeminentes no contexto de uma relativa preservação do funcionamento cognitivo e do afeto"13.

Tal especificação da paranoia respondia a uma tendência maior da psiquiatria ocidental, até então, que era distinguir um modo de loucura em que as funções de julgamento e os usos da linguagem eram, em larga medida, conservados em sua estrutura formal de outro no qual tais funções superiores eram eliminadas no interior de um processo de regressão, que, classicamente, foi chamado de "demência". Por isso, alguém, como Foucault, dirá:

[...] a demência é, de todas as doenças do espírito, esta que permanece mais próxima da essência da loucura. Mas da loucura em geral - da loucura sentida em tudo o que ela pode ter de negativo: desordem, decomposição do pensamento, erro, ilusão, não-razão e não-verdade ${ }^{14}$.

\footnotetext{
${ }^{12}$ Ver CRAIGHEAD, Edward; CRAIGHEAD, Linda; MIKLOWITZ, David. Psychopathology: history, diagnosis and empirical foundations. New Jersey: Wiley, 2008, pp. 402-434.

${ }^{13}$ DSM IV, p. 317. A respeito da noção de "delírio", que ainda parece dirigir a compreensão da paranoia, podemos afirmar que ela foi cristalizada no final do século XIX, servindo para descrever "[...] um ato de fala (ainda que o delírio possa, ocasionalmente, ser expresso em comportamento não-linguístico) compreendido pelo interlocutor como expressando uma crença (patológica) a respeito de si mesmo ou do mundo" (BERRIOS, German. The history of mental symptoms: descriptive psychopathology since the nineteenth century. Cambridge: Cambridge University Press, 1996, p. 112). Tal "crença errada" pode conservar coerência formal, embora tenha conteúdo ideacional distorcido.

${ }^{14}$ FOUCAULT, Michel. Histoire de la folie. Paris: Gallimard, 1962, p. 320.
} 
Essa dicotomia, tão bem caracterizada na distinção alemã entre Wahnsinn e Verrückheit, continuou na psicanálise com sua distinção entre esquizofrenia e paranoia. No entanto, ela tende a ser diminuída na psiquiatria contemporânea, que unificou todo o espectro das psicoses sob a categoria geral de "esquizofrenia".

Podemos ver nessa conservação relativa da estrutura cognitiva e afetiva na paranoia um traço importante. Alguns psicanalistas viram nela a indicação de um regime de participação em valores sociais e modos normatizados de raciocínio que dão forma à própria noção de personalidade. É pensando nisso que alguém como Jacques Lacan dirá, em uma tese de doutorado dedicada à paranoia: "A economia do patológico parece assim calcada sobre a estrutura normal"15. Isso porque ela absorve os modos formais de raciocínio e comportamento próprios à estrutura normal.

Nesse sentido, não é desprovido de interesse perceber como encontramos tal intuição em um trabalho profícuo de psicologia social como Massa e Poder, de Elias Canetti ${ }^{16}$. Essa absorção de modos formais de raciocínio e comportamento próprios à estrutura normal pode ser identificado, por exemplo, na presença, no interior da paranoia, de algo como um "vício da causalidade" e um "vício da fundamentação". Uma espécie de princípio de razão suficiente elevado à defesa patológica: nada acontece que não tenha uma causa. Assim, na "ontologia paranoica", não haverá lugar para noções como contingência e acaso. Por trás da máscara do novo, há sempre o mesmo. Tudo o que é desconhecido deve ser remetido a algo conhecido e referido ao doente. Isso leva o paranoico à necessidade compulsiva do desmacaramento. Ele quer que haja algo por trás dos fenômenos ordinários e só se acalma quando uma relação causal é encontrada.

Desse modo, é possível dizer que um dos traços fundamentais da paranoia, traço que fornece a base de sua certeza delirante e da incorrigibilidade de seus julgamentos, está vinculado à naturalização das estruturas e dos quadros narrativos de organização da experiência. Não é possível ao sujeito tomar distância de suas próprias construções, retificando criticamente suas pretensões a partir dos acasos e contingências da experiência, desconfiando de sua sistematicidade e de sua exigência absoluta de sentido e ligação, pois tais construções foram naturalizadas. Portanto, não seria incorreto ver, nesta forma imanente de adesão a suas próprias crenças, um

15 LACAN, Jacques. De la psychose paranoiaque dans ses rapports à la personalité. Paris: Seuil, 1975, p. 56. O que é, no fundo, uma derivação consequente da ideia freudiana, segundo a qual,: "[...] mesmo formações mentais tão extraordinárias, tão afastadas do pensamento humano habitual, tiveram origem nos mais universais e compreensíveis impulsos da vida psíquica" (FREUD, Sigmund. Observações psicanalíticas sobre um caso de paranóia. In: O caso Schreber e outros textos. São Paulo: Companhia das Letras, 2010, p. 24).

${ }^{16}$ CANETTI, Elias. Massa e poder. São Paulo: Companhia das Letras, 2005, p. 448-463 
efeito maior daquilo que em teoria social chamariamos simplesmente de reificação ${ }^{17}$. O que talvez nos permitiria dizer que a paranoia é uma sombra da razão, pois é o risco aberto quando ocorre uma reificação da própria estrutura do conhecimento.

Por outro lado, notemos como há um conjunto de valores políticos que parecem nortear o sofrimento paranoico. Falamos de unidade, identidade, controle e risco de invasão. Como se fosse questão de assegurar a posse e a unificação de um território a todo o momento ameaçado. Não é difícil perceber, já neste momento, como os motivos paranoicos parecem derivados de uma certa compreensão a respeito daquilo que uma ordem deve ser capaz de produzir.

\section{Paranoia e literatura: valores estéticos}

A fim de compreender melhor esse ponto, tentemos explorar, de maneira mais sistemática, tais valores sociais presentes na constituição mesma dos julgamentos delirantes e alucinações perceptivas paranoicas. Para tanto, vale a pena, inicialmente, insistir na relação possível entre paranoia e literatura, a fim de afirmar a existência de um paralelismo de forte potencial explanatório entre a constituição da paranoia como categoria clínica específica e a crise do romance moderno (como se também fôssemos obrigados a admitir que valores estéticos podem entrar na configuração de uma categoria clínica). Já Krafft Ebing aludia ao caráter "[...] barroco, romanesco e fantástico das ideias delirantes". Como se estivéssemos diante de um mau romance ${ }^{18}$. Observemos, por exemplo, o que está pressuposto em uma afirmação como:

[...] a predominância [da esfera intelectual inconsciente no comportamento paranóico] se produz através do caráter onírico, mole, geralmente romanesco e entusiasta destes indivíduos. Seus estados de espírito e depressões não motivadas, reminiscências de leituras ou do teatro continuam a se tecer no mais profundo de suas almas, depois surgem de repente sob a forma de concepções

\footnotetext{
${ }^{17}$ Exemplo ilustrativo de tal situação de reificação são considerações clínicas, como: "Os pacientes com transtornos de personalidade paranoide são incapazes de pensar: 'Parece que esta pessoa está tentando me prejudicar'. Em vez disto, eles sabem que a outra pessoa tem más intenções” (GABBARD, Glen. Psiquiatria psicodinâmica na prática clínica. Porto Alegre: Artmed, 2006, p. 301).

18 Vários foram os comentadores que observaram tal parentesco. Por exemplo, Postel e Quétel insistirão que os elementos definidores da paranoia são: “[...] a falta de fenômeno psicosensorial, a evolução fora da demência, a integridade intelectual, o funcionamento agudo da crítica, mas também a possibilidade de contar-se como história, talvez um pouco singular, mas verossímil, história que toma como modelo esse protótipo do relato novelístico - a escola francesa e a escola russa - cujas estruturas narrativas os trabalhos de Barthes e seus continuadores nos revelam" (POSTEL, Jacques; QUÉTEL, Claude (Org.); Historia de la psiquiatria. Cidade do México: Fondo de Cultura Econômica, 1987, p. 335).
} 
obsedantes e delírios primordiais para encontrar mais tarde expressão nas concepções delirantes da doença ${ }^{19}$.

Ou seja, trata-se de dizer que os delírios e alucinações não deixam de tecer relações com conteúdos romanescos, como se fosse questão de conseguir compor uma narrativa capaz de assegurar o sentido da existência. Isso nos permitirá nos perguntar em que a loucura se serve dos modelos de subjetividade em circulação, na cultura, para encontrar seu modo de expressão. Mais, ainda. Em que ela expõe algo de fundamental da natureza desses modelos?

Não deixa de ser interessante notar que, nesse sentido, a sistematização da paranoia é contemporânea da crise do romance moderno, no final do século XIX. A respeito do romance dessa época, com sua tendência a problematizar sua própria forma, a isolar o narrador em uma posição subjetiva cada vez mais distante da totalidade (pensemos, por exemplo, em um romance paradigmático desse período, Madame Bovary, de Flaubert, que não por acaso serviu de base para a constituição de um tipo de paranoia: o bovarismo ${ }^{20}$ ), um teórico como Gyorg Lukács dirá:

A elevação da interioridade a um mundo totalmente independente não é um mero fato psicológico, mas um juízo de valor decisivo sobre a realidade: essa auto-suficiência da subjetividade é seu mais desesperado gesto de defesa, a renúncia de toda a luta por sua realização no mundo exterior - uma luta já encarnada a priori como inútil e somente como humilhação ${ }^{21}$.

A recusa dessa cisão entre interioridade e exterioridade, feita com "gestos desesperados de defesa", com a megalomania de "elevações desmedidas do sujeito", é lida, por Lukács, através do desdobramento da temática hegeliana da perda de uma eticidade (Sittlichkeit) projetada na pretensa substancialidade ética da polis grega. Tal recusa encontrará na formação do romance moderno seu gesto maior. Daí uma afirmação como: "O romance é a epopéia de uma era para a qual a totalidade extensiva da vida não é mais dada de modo evidente, para a qual a imanência do sentido à vida tornou-se problemática, mas que ainda assim tem por intenção a totalidade"22. E se, desde o primeiro romance moderno (Dom Quixote), a loucura, juntamente com o crime, parecem sempre estar à espreita da narrativa, é porque

19 KRAFFT EBING. Traité de psychiatrie. Paris: Maloine, 1897.

${ }^{20}$ Ver, a esse respeito, KEHL, Maria Rita. Deslocamentos do feminino. São Paulo: Imago, 2008.

21 LUKÁCS, Gyorg. A teoria do romance, São Paulo: Editora 34, 2007, p. 119. Ou, ainda: “O processo segundo o qual foi concebida a forma interna do romance é a peregrinação do indivíduo problemático rumo a si mesmo, o caminho desde o opaco cativeiro na realidade simplesmente existente, em si heterogênea e vazia de sentido para o indivíduo, rumo ao autoconhecimento" (idem, p. 82).

${ }^{22}$ Idem, p. 55 
loucura e crime são marcas de um certo "desterro transcendental" 23 necessariamente tematizado pelo romance. Desterro que toca a própria estrutura formal do romance, já que ele deverá se tornar uma “[...] fusão paradoxal de componentes heterogêneos e descontínuos numa organicidade constantemente revogada"24.

Isso possibilita nos colocar uma questão de fundo. Se o próprio romance já sentia no seu interior as marcas da dissolução de uma possível apreensão correta da realidade, isso a ponto de Lukács compreender a produção romanesca do final do século XIX (como Tolstoi e Flaubert) a partir da noção de "romance da desilusão", então podemos dizer que o "romance paranoico" será o único lugar onde essa dissolução não será sentida. A paranoia será o romance que luta por não reconhecer a crise do romance, de seu narrador e de sua linguagem formal. Como se a paranoia fosse a impossibilidade desesperada de viver em um mundo marcado pela crise; como se ela fosse a criação de um mundo no interior do qual o conflito (e é sempre bom lembrar que lá onde há necessidade de reconhecimento da alteridade há sempre uma dinâmica conflitual de interpretações) e a crise são insuportáveis.

Isso talvez nos explique porque um teórico da literatura da segunda metade do século XX, como Christopher Lasch, ao desenvolver a tese de que o romance contemporâneo dos anos sessenta (de Thomas Pynchon ou mesmo o nouveau roman francês) estaria procurando estilizar a paranoia, refere-se a uma afirmação do protagonista de $O$ arco íris da gravidade, de Pynchon: "Se há uma coisa reconfortante - a religião, se se quer -, frente à paranóia, há também ainda a antiparanóia, onde nada está ligado a nada, uma condição que poucos de nós poderíamos suportar por muito tempo". O que o faz afirmar:

A paranóia serve como um substituto da religião, porque ela oferece a
ilusão de que a história obedece a algum princípio interno de racionalidade,
o que é pouco animador, mas preferível, de qualquer forma, aos terrores da
antiparanóia [...] Para Pynchon, isso significa que a arte fabrica uma ilusão de
sentido - um "complô" no qual "todas as peças se encaixam" - sem a qual o
peso da individualidade torna-se insuportável"

Ou seja, contra a experiência da fragilidade dos mecanismos de produção e estabilização do sentido, a própria literatura começaria a mimetizar o procedimento paranoico de reconstrução da unidade narrativa através de interpretações delirantes, marcadas pelas temáticas da perseguição, do complô, da grandeza e da erotomania. Aceita a ruptura entre o Eu e o meio social, como

\footnotetext{
${ }^{23}$ Idem, p. 61

${ }^{24}$ Idem, p. 85.

${ }^{25}$ LASCH, Christopher. O mínimo eu. São Paulo: Brasiliense, 1985, p. 142. 
afirmava Lukàcs, a paranoia aparece como um meio para construir um meio social privado e narcísico que aspira a valer por toda realidade.

Se seguirmos essa ideia da paranoia como romance que luta por não reconhecer a crise do romance, poderemos entender melhor algumas considerações fundamentais de Jacques Lacan, a respeito da linguagem na paranoia.

Em vários contextos, Lacan insiste no caráter reificado da linguagem na psicose. Linguagem sem distância entre as palavras e as coisas, sem aquilo que Lacan chamava de "perpétua possibilidade de uma inversão do signo em função da totalidade dialética da posição do indivíduo" ${ }^{26}$. A indicação de tal caráter é tão importante que Lacan dirá, a respeito de uma apresentação de caso:

Eu me recusei a aceitar o diagnóstico de psicose por uma razão decisiva. É que não havia nenhuma destas perturbações na ordem da linguagem. Nós devemos exigir, antes de aceitar o diagnóstico de psicose, a presença de tais perturbações. ${ }^{27}$

Lacan descreve algumas características dessas perturbações psicóticas da linguagem: ausência substancial de metáforas, presença de neologismos, significações estanques. A respeito dos neologismos, que normalmente compõem o delírio psicótico, Lacan dirá: "É uma significação que não envia a nada, a não ser a ela mesma, ela fica irredutível. O doente sublinha que a palavra tem peso em si mesma" ${ }^{\prime 28}$. Encontramos tal inércia também nas considerações de Lacan a respeito da economia do inconsciente na psicose. Se é verdade que, na psicose, o inconsciente não é recalcado, apresentando-se a céu aberto: "Contrariamente ao que poderíamos acreditar, que ele esteja aí não significa em si mesmo resolução alguma mas, ao contrário, uma inércia toda particular" ${ }^{29}$. O que não poderia ser diferente, já que essa inércia indica simplesmente reificação.

Sobre essa inércia própria à linguagem psicótica, lembremos que Freud caracterizou tal linguagem como "[...] uma linguagem que trata as palavras como coisas" ${ }^{\prime 3}$. Consideração ilustrada pelo exemplo da analisanda de Victor Tausk, conduzida à clínica após uma disputa com seu amante e portando a seguinte

${ }^{26}$ LACAN, Jacques. Le séminaire III: les psychoses, Paris: Seuil, 1981, p. 32. Até porque “[...] a coisa que esquecemos [e que o paranóico é o primeiro a esquecer] é que aquilo de próprio ao comportamento humano é o movimento dialético das ações, dos desejos e dos valores, que os faz não apenas modificálos a todo instante, mas de uma maneira contínua, passando mesmo a valores estritamente opostos em função de um desvio do diálogo" (idem).

${ }^{27}$ Idem, p. 106.

${ }^{28}$ Idem, p. 43.

${ }^{29}$ Idem, p. 164.

${ }^{30}$ FREUD, Sigmund. Gesammelte Werke, vol. X. Frankfurt: Fischer, 1999, p. 298. 
reivindicação: "Meus olhos (Augen) não estão como devem estar, eles estão revirados (verdreht)". Resultado da coisificação da metáfora: "[...] meu amado é um hipócrita, um Augenverdreher". Pois, se Freud afirma que, na esquizofrenia, há a predominância da relação de palavra sobre a relação de coisa, é porque as palavras foram coisificadas. Isso leva Lacan a afirmar que, na psicose, o uso de metáforas é limitado devido a essa natureza coisificada da linguagem, natureza que impede ao sujeito tomar distância de seu próprio dizer. O que explicaria por que os psicóticos não são poetas:

Schreber não nos introduz em uma dimensão nova da experiência. Há poesia cada vez que um escrito nos introduz em um mundo outro e, nos fornecendo a presença de um ser, de uma certa relação fundamental, o faz advir também nosso [...] A poesia é criação de um sujeito assumindo uma nova ordem de relação simbólica ao mundo. Não há nada disto nas Memórias de Schreber ${ }^{31}$.

Se não há nada disso nas Memórias, de Schreber, é porque assumir uma nova ordem de relação simbólica ao mundo não consiste em criar narrativas fantásticas ou em fixar-se em um delírio de interpretação irredutível. Trata-se, na verdade, de, inicialmente, reconhecer a natureza simbólica da relação ao mundo, sair do domínio de uma linguagem realista, e isto é impossível para o psicótico. Um psicanalista lacaniano, Octave Manonni, compreendeu claramente isso, ao afirmar:

A questão sobre a qual uma teoria da paranóia teria de responder é de onde vem o fato de um sujeito como Schreber não poder sair de um discurso a ser tomado ao pé da letra, um discurso absoluto, sagrado ou positivamente verdadeiro. Ele não pode tomar, em relação a este discurso, a distância que abriria um lugar para a fantasia à despeito do fantástico ${ }^{32}$.

Se esse for realmente o caso, então a boa questão será: por que isso é impossível ao paranoico - "sair de um discurso a ser tomado ao pé da letra"? Certamente, tal discurso reificado responde, como já foi dito, à profunda impossibilidade de mediação da alteridade ou, para falar com Lacan, “ [...] impossibilidade de fazer alguma mediação simbólica entre o que é novo e o próprio sujeito"33. Todavia, a boa questão é: por que tal mediação se tornou impossível? Uma resposta possível seria:

${ }^{31}$ LACAN, ibidem, p. 91. É, no fundo, um problema de impossibilidade de mediação que aparece na definição canônica de Lacan a respeito da psicose: “[...] a falta de um significante leva necessariamente o sujeito a colocar em causa o conjunto dos significantes. Eis a chave fundamental do problema da entrada na psicose" (idem, p. 229). Ou seja, a impossibilidade de inscrição simbólica, de mediação de um dado da experiência subjetiva, estruturador para o sujeito, coloca em causa a própria estrutura geral de organização da experiência.

32 MANONNI, Octave. Clefs pour l'imaginaire. Paris: Seuil, 1969, p. 98.

${ }^{33}$ LACAN, ibidem, p. 101. 
porque o paranoico não compreende o que é exatamente uma ordem social, o que devemos esperar de uma ordem social e qual a natureza de suas descrições.

\section{UMA CRISE DA ORDEM DO MUNDO}

Não é por acaso que questões dessa natureza parecem animar este que é o caso mais conhecido de paranoia no interior da literatura clínica, a saber, o famoso caso de Daniel Paul Schreber. Vale a pena, pois, voltarmos a algumas elaborações gerais referentes ao caso.

Ao ser internado, Schreber desenvolve um quadro delirante em que temáticas religiosas e científicas se misturam, para descrever uma crise profunda na "ordem do mundo". Sua visão de mundo parte da afirmação de que a alma humana está contida nos nervos do corpo, algo comparável a fios de linha muito finos. Deus também é, desde o início, apenas nervo, e não corpo, portanto, algo aparentado à alma humana. Até o momento de crise, a situação era tal que Deus deixava abandonados a si mesmos o mundo criado por ele e os seres orgânicos. Uma intervenção imediata de Deus no destino dos indivíduos, via de regra, não acontecia apenas em situações particulares. Essa "conexão nervosa” entre Deus e a criatura não podia se tornar regra:

Os nervos de homens vivos, sobretudo em estado de uma excitação muito intensa,
possuem uma tal força de atração sobre os nervos de Deus que Deus não
poderia mais livrar deles, ficando portanto ameaçado em sua própria existência ${ }^{34}$.

Por essa razão, relações regulares entre Deus e as almas humanas só ocorriam depois da morte. Então, Deus podia, sem perigo, se aproximar dos cadáveres para atrair para si os nervos em direção à beatitude. Isso significava que Deus não tinha onisciência e onipresença em relação aos seres humanos. Ele só tecia relações com cadáveres, já que os nervos humanos conservavam todas as impressões recebidas durante a vida.

Deus via um homem vivo só por fora, não existindo, como regra geral, uma onisciência e uma consciência de Deus com relação ao interior das pessoas vivas. Mesmo o eterno amor divino, fundamentalmente, só existia para a criação como um todo ${ }^{35}$.

Tais nervos passavam por uma purificação na qual as almas aprendiam a língua falada por Deus, que - não podia ser diferente - era uma espécie de alemão

\footnotetext{
${ }^{34}$ SCHREBER, ibidem, p. 36.

35 Idem, p. 48. 
arcaico cheio de palavras de sentidos opostos (recompensa era punição, veneno era alimento, profano era sagrado etc.). As almas completamente depuradas pelo processo de purificação subiam ao céu, atingindo a beatitude. Tal beatitude consistia num estado de gozo ininterrupto, associado à contemplação de Deus. A beatitude masculina ficava um grau acima da feminina; esta última era, na verdade, um "[...] sentimento ininterrupto de volúpia"36.

Tal construção teria entrado em crise devido aquilo que Schreber chama de "assassinato de alma" e que teria sido produzido por seu médico, Dr. Flechsig. Tal assassinato estaria sendo imputado a Schreber. Trata-se de uma espécie de "abuso" das conexões nervosas. Deus teria concedido à família Flechsig a possibilidade de ter conexões nervosas e de receber inspirações divinas. No entanto, os Flechsig procuraram "reter os raios divinos" impedindo, com isso, que a estirpe dos Schreber pudesse ter relações de maior proximidade com Deus. Daí a noção de "assassinato de alma", ou seja:

A entrega de uma alma a outra, seja para conseguir uma vida terrena mais longa, seja para se apropriar das forças espirituais desta, seja ainda para obter uma espécie de imortalidade pessoal ou alguma outra vantagem ${ }^{37}$.

Schreber acreditava que Flechsig estabelecera uma conexão nervosa com ele, falando com seus nervos sem estar presente em pessoa, interferindo em seus nervos ao provocar uma "coação a pensar" de maneira ininterrupta. Tal assassinato abalou a ordem do mundo, criando uma crise que teria colocado o próprio Deus em perigo. Abalo este que permitiu a Schreber ter uma relação ininterrupta com os raios divinos. Tal ligação indissolúvel entre Deus e Schreber teria provocado uma crise de tal tamanho que o fim do mundo teria ocorrido, sendo Schreber o único homem verdadeiro que ainda restava. As poucas figuras humanas que ele via seriam "homens feitos às pressas" produzidos por milagres. Schreber chega a afirmar que tudo o que acontecia se referia necessariamente a ele:

Desde que Deus entrou em conexão nervosa exclusiva comigo, eu me tornei para Deus, num certo sentido, o homem, ou o único homem em torno do qual tudo gira, ao qual tudo deve se referir e que por isso, também do seu próprio ponto de vista, tem de referir a si mesmo todas as coisas ${ }^{38}$.

\footnotetext{
${ }^{36}$ Idem, p. 40.

${ }^{37}$ Idem, p. 46. Lacan compreendeu que "[...] trata-se algo que tem essencialmente relações com as origens do Eu, a algo que é, para o sujeito, a eclipse de seu ser, desta imagem na qual ele se reflete sob o nome de Eu" (LACAN, ibidem, p. 236).

${ }^{38}$ Idem, p. 205.
} 
Notemos como Deus não aparece em seus delírios enquanto figura de onipotência. Tanto que "[...] a Ordem do mundo não fornece, nem mesmo a Deus, os meios para destruir a razão de um homem" "39. Dado importante, pois nos encontramos às voltas com uma tentativa de dar forma à limitação do poder do Outro, à incapacidade do Outro tudo saber e poder tudo saber. De certo modo, Schreber procura dar forma para a experiência de uma ordem não apenas muito invasiva, que está em conexão direta com ele mesmo. Ele quer falar de uma ordem que se impõe de maneira totalmente exterior, que é incapaz de saber o que realmente se passa com aqueles que ela ordena. Uma ordem cuja força é proporcional à sua cegueira. Em suma, uma ordem em crise. Algo que não deixa de nos remeter a uma situação histórica precisa de crise da ordem social que assombrava a cultura europeia do final do século XIX e começo do século XX. Basta lembrarmos, aqui, dos estudos clássicos de Emile Durkheim sobre a anomia social e de Max Weber sobre o desencantamento do mundo.

No entanto, tudo se passa como se essa experiência de crise não pudesse, por alguma razão, ser realmente simbolizada, ser realmente vivida pelo sujeito. Falta ao sujeito a gramática para a elaboração de experiências de crise. Elas só podem ser elaboradas sob a forma de delírios e de alucinações, elas pedem um complemento que acaba por ganhar a forma de delírios místicos capazes de reconstruir o sentido de um mundo em decomposição, fornecer um sentido cosmogônico para a decomposição do mundo. Nesse sentido, a paranoia de Schreber não é exatamente a figura de mente fragilizada, mas de uma mente para qual é impossível pensar a fragilidade de nossas imagens de mundo. Como se ela representasse, de uma maneira extremamente acabada, a reação quixotesca contra uma ordem em decomposição, que ameaça nos jogar em um mundo onde precisaremos nos deparar continuamente com aquilo que é radicalmente contingente.

Assim, sua paranoia será a costura de um mundo em decomposição que se apoiará em ideias centrais para a constituição de toda personalidade, como constituição de um ideal enquanto missão simbólica (ideal capaz de organizar as contingências do desenvolvimento, tendo em vista a realização de um projeto), a organização narrativa e unificada dos fatos que compõe o desenvolvimento de um sujeito, entre outros.

Por outro lado, se voltarmos à interpretação fornecida por Freud a respeito desse caso, encontraremos em seu fundamento a compreensão de que as temáticas delirantes eram formas de elaboração desesperada de um conflito infantil com o pai, travestido de conflito entre Schreber e Deus. Sabemos que, para uma certa perspectiva psicanalítica, tais conflitos são centrais, porque eles fornecem a matriz de inteligibilidade para modelos gerais de funcionamento

${ }^{39}$ Idem, p. 222. 
da autoridade em outros níveis da vida social. Mas a questão que devemos responder é: por que conflitos familiares absolutamente "normais" no processo de constituição de todo e qualquer sujeito serão vivenciados por Schreber de forma tão traumática? Uma resposta possível consiste em dizer que o conflito psicótico com a autoridade paterna é uma maneira de procurar suplementar a fraqueza normativa de tal autoridade, suplementar sua crise de legitimidade, mas através da constituição fantasmática de sua onipotência. Isso faz com que o sujeito e seu corpo se transformem em campo de demonstração de tal onipotência. Maneira de aproximar demais o princípio de autoridade, de "acreditar demais" em seu pai. O resultado dessa aproximação excessiva só pode ser uma lei que legisla através de uma intervenção direta nos modos de gozo do sujeito. A esse respeito, podemos, talvez, seguir a intuição de Eric Santner:

Schreber descobre que o poder não apenas proíbe, modera, diz "não", mas
pode também funcionar no sentido de intensificar e ampliar o corpo e suas
sensações. Dito de maneira um pouco diferente, Schreber descobre que a
autoridade simbólica em estado de emergência é transgressora, exibe uma
obscena superproximidade do sujeito: ou seja, nas palavras dele, exige o gozo ${ }^{40}$.

A ideia fundamental, aqui, é: o pai de Schreber era, em certo sentido, “[...] mais pai do que os pais típicos; encarnava um excedente de poder, influência e autoridade paternos que predispunha à transfiguração realizada na imaginação perturbada de seu filho" ${ }^{\prime 1}$. Na verdade, esse excedente ocorre, o poder precisa chegar perto demais, exatamente quando ele não é mais capaz de assegurar uma ordem estável. Então, ele deve estar em todos os poros, ele deve auscultar cada passo dos sujeitos que ele procura submeter, ele deve se fazer ouvir em cada exigência de gozo, pois cada passo pode levar tais sujeitos longe do controle do poder, cada poro pode deixar escapar o que deveria ser submetido. Esse poder é típico de uma época assombrada pelo fantasma de sua própria dissolução, época que se defronta com a emergência de fatores que ela não sabe mais como controlar. Esta época só encontrará estabilidade através de estratégias que veremos claramente em jogo na paranoia.

\section{O FUNDO PARANOICO DE TODA PERSONALIDADE}

Aqui, podemos chegar ao nosso desenvolvimento final. Freud costumava dizer que a conduta patológica expõe, de maneira ampliada (Freud fala de

${ }^{40}$ SANTNER, Eric. A Alemanha de Schreber: a paranóia à luz de Freud, Kafka, Foucault, Canetti, Benjamin, Rio de Janeiro: Jorge Zahar, 1997, p. 47.

${ }^{41}$ Idem, p. 63. 
Vergrösserung e Vergröberung), o que está realmente em jogo no processo de formação das condutas sociais gerais. É dessa forma que devemos interpretar uma metáfora maior de Freud: "Se atiramos ao chão um cristal, ele se parte, mas não arbitrariamente. Ele se parte, segundo suas linhas de clivagem, em pedaços cujos limites, embora fossem invisíveis, estavam determinados pela estrutura do cristal”"42. O patológico é esse cristal partido que, graças à sua quebra, fornece a inteligibilidade do comportamento definido como normal. Nesse sentido, podemos nos perguntar se a paranoia não expõe, como em uma lente de aumento, a natureza do modo de formação da personalidade que determina a figura da subjetividade moderna.

\begin{abstract}
Em decorrência, poderíamos voltar à hipótese de existência de uma espécie de fundo paranoico em todo processo de constituição da personalidade. No fundo, trata-se de levar a sério a ideia de Jacques Lacan, enunciada ao comentar a razão pela qual ele relutou em republicar sua tese de doutorado sobre as relações entre psicose paranoica e personalidade: "Se resisti por tanto tempo à republicação de minha tese, é simplesmente pelo seguinte, é que a psicose paranóica e a personalidade como tal não têm relações, simplesmente por isso, porque são a mesma coisa" ${ }^{43}$.
\end{abstract}

No entanto, não se trata de, simplesmente, impor uma similitude completa entre formação de um Eu como unidade psicológica e estrutura paranoica. Que no seu processo de formação, o Eu coloque em circulação motivos e processos que fornecerão o fundamento da paranoia, isto não significa que estamos exatamente diante do mesmo fenômeno. No fundo, isso significa duas coisas. Primeiro, que a paranoia talvez deva ser compreendida como a tentativa desesperada de constituir um Eu, lá onde esse processo não é completamente possível. Dessa maneira, devemos compreender claramente de onde vem a flexibilidade que permite aos sujeitos modernos evitarem a paranoia, mesmo colocando em circulação processos que a constituem. Qual é, nesse caso, a diferença qualitativa entre normalidade e patologia?

Nesse contexto, vale lembrar o que realmente estava em jogo na centralidade do problema da entrada no universo simbólico para a explicação lacaniana das psicoses. Deve-se ter em mente, a esse respeito, como uma estrutura simbólica (ou, se quisermos, uma ordem socia) não é, para Lacan, apenas aquilo que determina previamente os modos de relação sociais. Lacan insistia em que a Lei social que estrutura o universo simbólico não era uma lei normativa no sentido forte do termo, ou seja, uma lei que enuncia claramente o que devo fazer

42 FREUD, ibidem, p. 64.

${ }^{43}$ LACAN, Jacques. Séminaire XXIII: Le sinthome. Paris: Seuil, 2005, p. 53. 
e quais condições devo preencher para segui-la. Esta é uma questão central que costuma gerar confusões. A Lei simplesmente organiza distinções e oposições que, em si, não teriam sentido algum. Assim, por exemplo, a Lei da estrutura de parentesco pode determinar topicamente vários lugares, como "filho de...", "pai de...", "cunhada de...", mas esses lugares não têm em si nenhuma significação normativa, nenhuma referência estável. Por isso, nunca sei claramente o que significa, por exemplo, ser "pai de...", mesmo tendo consciência de que ocupo atualmente tal lugar. Só posso saber o que um pai é, o que devo fazer para assumir a autoridade e enunciar a norma à condição de acreditar em uma certa impostura. É essa ausência de conteúdo que Lacan tem em vista, ao afirmar que a Lei sóciosimbólica é composta por significantes puros, desprovidos de denotação; que ela é uma "cadeia de significantes".

Dessa forma, podemos entender melhor a profícua ideia lacaniana de que uma estrutura simbólica é aquilo que nos permite nos relacionarmos com a experiência da falta, na determinação do objeto do desejo, assim como nos relacionarmos com a experiência da fragilidade do sentido e das operações de identidade. Poder se relacionar a tais experiências é fundamental para que situações de fragilização das experiências de sentido e de identidade, assim como de indeterminação do objeto de desejo, não sejam vivenciadas como situações catastróficas de vulnerabilidade absoluta para o sujeito. No entanto, é exatamente isso que ocorre nos casos de psicose. Assim, a entrada bem sucedida no interior da estrutura simbólica está intimamente vinculada à capacidade de saber lidar com isso que Lacan chama de "falta". A função de uma ordem social talvez não seja outra que esta.

Por fim, seria necessário mostrar como essa maneira de evitar a paranoia não é sem deixar traços. Ou seja, há algo no processo de formação do Eu moderno que nos deixa vulneráveis a um certo retorno da paranoia. A teoria social da Escola de Frankfurt, em especial aquela desenvolvida por Theodor Adorno e por Max Horkheimer, foi fundamental para demonstrar como impasses sociopolíticos no interior de nossas formas de vida, impasses estes que podem dar formas à políticas totalitárias e de segregação, não são simples acidentes advindos de momentos de crise. Eles são marcas sempre inscritas em nossas formas de vida, devido, entre outras coisas, ao processo de formação de nossa própria subjetividade. Não foi por outra razão que tais autores usaram uma categoria clínica como a "paranoia" para explicar a natureza dos vínculos sociais no interior do fascismo.

Nesse sentido, se o reconhecimento de nossa vulnerabilidade é condição fundamental para desenvolver ações que impeçam múltiplas formas de sofrimento social, o estudo de categorias clínicas, como a paranoia, talvez nos auxilie no conhecimento do que somos, de como somos formados e quais são nossas linhas 
de clivagem, ou seja, onde quebraremos quando jogados no chão, onde quebramos com mais facilidade. Insistiria neste ponto que pode ter consequências tanto clínicas quanto políticas: o reconhecimento de nossa vulnerabilidade é condição fundamental para sabermos como lidar com a instabilidade de nossas formas de vida. Desse modo, o único que é incapaz de reconbecer sua vulnerabilidade e sua insegurança (no sentido de conseguir inscrever tal situação em um dinâmica social de reconhecimento), de senti-la como insuportável, é exatamente o paranoico. Uma impossibilidade vinda de uma maneira extremamente peculiar de participação e defesa de valores políticos e estéticos em decomposição. Contudo, por outro lado, é bem provável que um dos traços definidores do comportamento normal seja exatamente sua capacidade de não se quebrar completamente, ao reconhecer a vulnerabilidade e a insegurança de suas construções. Não se quebrar completamente, quando se está em crise.

SAFATTLE, V. Paranoia as social catastrophe: on the problem of the genesis of clinical concepts. Trans/Form/Ação, Marília, v. 34, n.2, p. 215-236, 2011.

ABSTRACT: This article aims to discuss the relationship between the constitution of paranoia as clinical category and social-aesthetical experiences of crisis. This is a way to ask for the relationships between clinical categories and values, processes that came from the field of politics and aesthetics.

KEYWORDS: Paranoia. Freud. Lacan. Social suffering. Literature. Language.

\section{REFERÊNCIAS}

AGUIAR, Adriano. A psiquiatria no divã. Rio de Janeiro: Relume Dumará.

BERRIOS, German. The bistory of mental symptoms: descriptive psychopathology since the nineteenth century. Cambridge: Cambridge University Press, 1996.

CANETTI, Elias. Massa e poder. São Paulo: Companhia das Letras, 2005.

CANGUILHEM, Georges. O normal e o patológico. Rio de Janeiro: Forense, 2002.

CRAIGHEAD, Edward; CRAIGHEAD, Linda; MIKLOWITZ, David. Psychopathology: history, diagnosis and empirical foundations. New Jersey: Wiley, 2008.

FOUCAULT, Michel. Naissance de la clinique. Paris: PUF, 2005.

FREUD, Sigmund. Gesammelte Werke, vol. X. Frankfurt: Fischer, 1999.

GABBARD, Glen. Psiquiatria psicodinâmica na prática clínica. Porto Alegre: Artmed, 2006.

KEHL, Maria Rita. Deslocamentos do feminino. São Paulo: Imago, 2008. 
SAFATTLE, $V$.

LACAN, Jacques. Le séminaire III: les psychoses. Paris: Seuil, 1981.

; Le séminaire XXIII: Le sinthome. Paris: Seuil, 2005.

LASCH, Christopher. O minimo eu. São Paulo: Brasiliense, 1985.

LUKÁCS, Gyorg. A teoria do romance. São Paulo: Editora 34, 2007.

MANONNI, Octave. Clefs pour l'imaginaire. Paris: Seuil, 1969

NIETZSCHE, Friedrich. A gaia ciência. In: Obras incompletas. São Paulo: Nova Cultural, 1987.

POSTEL, Jacques; QUÉTEL, Claude (Org.). Historia de la psiquiatria. Cidade do México: Fondo de Cultura Econômica, 1987.

SANTNER, Eric. A Alemanha de Schreber: a paranóia à luz de Freud, Kafka, Foucault, Canetti, Benjamin. Rio de Janeiro: Jorge Zahar, 1997.

SIMANKE, Richard. A formação da teoria freudiana das psicoses. Belo Horizonte: Loyola, 2008.

Recebido em: 7 de abril de 2011

Aprovado em: 14 de junho de 2011 